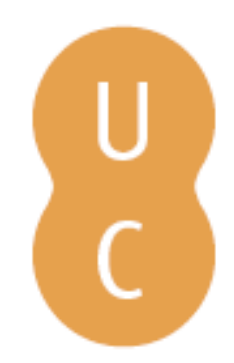

\title{
pompalina
}

\section{El Banquete de los Siete Sabios de Plutarco y los temas de sabiduría práctica}

Autor(es): $\quad$ Vela Tejada, José

Publicado por: Imprensa da Universidade de Coimbra; Centro de Estudos Clássicos e

URL

persistente: URI:http://hdl.handle.net/10316.2/32035

DOI: $\quad$ DOI:http://dx.doi.org/10.14195/978-989-8281-17-3_42

Accessed : $\quad$ 26-Apr-2023 15:09:51

A navegação consulta e descarregamento dos títulos inseridos nas Bibliotecas Digitais UC Digitalis, UC Pombalina e UC Impactum, pressupõem a aceitação plena e sem reservas dos Termos e Condições de Uso destas Bibliotecas Digitais, disponíveis em https://digitalis.uc.pt/pt-pt/termos.

Conforme exposto nos referidos Termos e Condições de Uso, o descarregamento de títulos de acesso restrito requer uma licença válida de autorização devendo o utilizador aceder ao(s) documento(s) a partir de um endereço de IP da instituição detentora da supramencionada licença.

Ao utilizador é apenas permitido o descarregamento para uso pessoal, pelo que o emprego do(s) título(s) descarregado(s) para outro fim, designadamente comercial, carece de autorização do respetivo autor ou editor da obra.

Na medida em que todas as obras da UC Digitalis se encontram protegidas pelo Código do Direito de Autor e Direitos Conexos e demais legislação aplicável, toda a cópia, parcial ou total, deste documento, nos casos em que é legalmente admitida, deverá conter ou fazer-se acompanhar por este aviso.

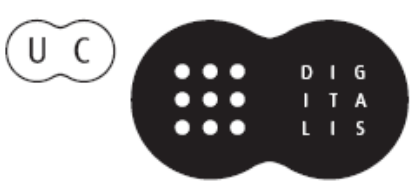




\section{Symposion and Philanthropia in Plutarch}

\section{José Ribeiro Ferreira, Delfim Leão Manuel Troster e Paula Barata Dias (eds.)}

IMPRENSA DA UNIVERSIDADE DE COIMBRA 


\title{
El Banguete de los Siete Sabios de Plutarco Y LOS TEMAS DE SABIDURÍA PRÁCTICA ${ }^{1}$
}

\author{
José Vela Tejada \\ Universidad de Zaragoza
}

\begin{abstract}
The aim of this article is to study why Plutarch makes use of the literary tradition of symposia to place the legend of the Seven Sages. Instead of that we should expect, given the hold of Plato over his work, Plutarch relegates philosophical argument to a type of dialogue focusing on aspects of practical wisdom. In our opinion, the explanation of this apparent contrast must be analyzed from a double and complementary perspective: first, by considering the protagonists of that fictitious meeting, the Seven Wise Men, the paradigm of archaic wisdom, which combined both practical and intellectual learning; second, as a result, the suitability of form and content to a symposiac framework deeply rooted in the literary tradition, just as it is attested by the early patterns of the fourth century BC: Xenophon and Plato.
\end{abstract}

1. Plutarco sitúa la leyenda de los Siete Sabios dentro de la tradición de Banquetes $^{2}$. Sin embargo, en contra lo que cabría esperar, dado el ascendiente del maestro Platón sobre el de Queronea ${ }^{3}$, en dicho encuentro legendario nuestro autor subordina la argumentación filosófica a un tipo de diálogo en el que predomina la atención a aspectos de sabiduría práctica ${ }^{4}$. En efecto, aunque se enmarca dentro del género literario del symposion ${ }^{5}$, el contenido de la obra parece acercarse más a la colección de saberes y conocimientos de la versión de Jenofonte o de los Deipnosofistas de Ateneo, que a la discusión filosófica de Platón ${ }^{6}$. Ello, unido a otras particularidades de la obra, como que la lista de los Sabios no se corresponda con la del diálogo Sobre la E de Delfos, llevó a la crítica dieciochesca y decimonónica a dudar de su adscripción a Plutarco, filiación generalmente admitida desde la auctoritas de Wilamowitz ${ }^{7}$. Y es que,

${ }^{1}$ La realización de este trabajo ha tenido lugar en el marco del Proyecto de Investigación HUM 2007-64772, auspiciado por la Dirección General de Investigación (Ministerio de Educación).

${ }^{2} \mathrm{Al}$ respecto, fueron canónicos los trabajos de U. von Wilamowitz, 1890, G. Hauck, 1893, en particular, pp. 4-24, y el más reciente B. SNELL, 1966, pp. 115-8.

${ }^{3}$ Sin embargo, para J. Mossman, 1997, p. 121, "Given such Platonic authority, it is hardly surprising that Plutarch decided to attempt a variation on the theme, and the result is the Dinner of the Seven Wise Men".

${ }^{4}$ Como se desprende, en particular, de su comparación con las Quaestiones Convivales (para J. Mossman, 1997, p. 120, junto a Ateneo, ejemplos de "prescriptive symposion literature"). Mas, con F. Rodríguez Adrados, 1996, p. 137, las vemos más próximas a los Problémata syssytiká de Aristóteles y no en relación directa con los Banquetes, pues carecen de una "intención dramática". Como indica Gallardo, 1972, p. 188, en nuestra pieza asistimos a un tipo literario muy afín al clásico. Para más información vid. S.-T. TEOdonsson, 1996, en particular, pp. 39-47, y la revisión plutarquea de E. Suárez de la Torre, 2005.

${ }^{5}$ Al respecto, cf. C. Morales Otal \& J. García López, 1986, p. 209 sqq., con referencias a las propuestas de J. Defradas, 1985, pp. 7-35, y D. E. Aune, 1972, pp. 51-60.

${ }^{6}$ Sobre esta cuestión vid. nuestra revisión en J. Vela Tejada, 2007, pp. 29-47.

${ }^{7}$ U.von Wilamowitz, 1890, 196-7. Sobre la autoría véase la revisión de C. Morales Otal 
como ya pudimos apreciar en el anterior Simposio plutarqueo ${ }^{8}$ en la synkrisis del tratamiento de la figura de Solón en el Bios y en el Banquete, el tipo de forma y contenidos literarios escogido por el de Queronea determinan el uso de la tradición?.

En nuestra opinión, la explicación a este aparente contraste ha de buscarse desde una perspectiva complementaria: los propios protagonistas del ficticio encuentro, los Siete Sabios, paradigma del ideal arcaico de sabiduría, que combina sabiduría práctica e intelectual ${ }^{10}$; en segundo lugar, y como consecuencia, la adecuación de contenido y forma a un marco simposiaco de honda raigambre en la tradición literaria ${ }^{11}$.

2. En la misma línea apuntada sobre las dudas de la autenticidad, se ha insistido en las dificultades estructurales de interpretación de la pieza ${ }^{12}$, las

\& J. García López, 1986, pp. 210-2.

${ }^{8}$ Cf. J. Vela Tejada, 2008, pp. 501-14.

${ }^{9}$ Para M.-L.Paladini, 1956, p. 409, Plutarco "sembri considerare il lato pratico ed operante della sapienza dei Savi. Ciò è indizio dell'uso di una fonte peripatetica”, que podría ser Dicearco, quien en su Bíor $\varphi \imath \lambda \sigma^{\prime} \varphi_{\varphi} \omega \nu$ habría fijado el perfil de los Sabios como expertos en la práctica política (según la información de D. L. I 40, Dicearco definió a los sabios no como sofoi ni filósofoi sino synetoi y nomothetikoi). Más adelante (pp. 410-1), añade la impronta de Hermipo y su Пвpi $\tau \tilde{\omega} \nu \sigma \circ \varphi \tilde{\omega} \nu$ en la elaboración de material didáctico con fines retóricos. En la misma línea se pronuncia G. J. D. Aalders, 1977, p. 28: "Plutarch will have known (a substantial part of) this literature; he will also have been influenced by it, and have made use of it, when he decide to describe a simposium of the Seven Wise Men".

${ }^{10}$ Así, R. P. Martin, 1993, p. 119, define a los Sabios como "practical men, political advisers or tyrants", y A. Busine, 2002, p. 94, cataloga el opúsculo como "une sorte d'apologie de la sagesse grecque".

${ }^{11}$ En efecto, aunque ya en el siglo $\mathrm{V}$ a.C. tenemos referencias a través de los sofistas (Critias F 4 D elogia el simposio espartano), el género simposiaco como tal conoce los primeros antecedentes en el siglo IV. No cabe duda de la influencia de Platón (cf.J. Mossman, 1997, p. 120: "a very wellestablished genre, dominated by Plato's Symposium"). Sin embargo, el testimonio de Jenofonte resulta aquí imprescindible para comprender la adaptación de una amplia tradición de dichos en nuevas formas conversacionales en el ámbito de la prosa de instrucción: en Memorables (cf. V.J. GraY, 1998, pp. 159-77, cap. IX, “The tradition of instructional literature”), en la tradición de anécdotas de hombres sabios del Hierón (V.J. GraY, 1986, p. 115 sqq.), con Simónides como el primero de ellos, y en el Banquete de corte socrático, obra que tiene su origen, en palabras de V.J. GraY, 1992, p. 74, "as a literary genre in the adaptation, development and transformation of a wider collection of stories about what the wise men of old said and did at their symposia". En este sentido, D. L. Gera, 1993, pp. 132-91, estudiando "The Symposia of the Cyropaedia", demuestra el perfecto conocimiento del autor del marco literario simposiaco, adaptado al mundo persa (vid., asimismo, M.-P. NoËL, 2006, p. 144). No sorprende, por tanto, como apreciara G. J. D. Aalders, 1977, p. 32 y 1982, p. 62, la familiaridad de Plutarco con el Banquete de Jenofonte (cf. Praec. 823).

${ }^{12}$ Así, por ejemplo, J.Mossman,1997, p.122, atribuye su diversidad al carácter conversacional: "the structure is very delicately hinged together and takes some time to perceive". Sin embargo, ya J. Defradas, 1985, p. 178, observaba que "tout le plan du Banquet répond au schéma suivi par Platon: le préambule dramatique, la première partie morcelée en un dialogue fait de courtes répliques, la seconde partie, constituée d'exposés plus substantiels, cette conclusion abrupte enfin, qui donne l'impression que bien des questions restent en suspens et que l'auteur fuit devant une conclusion". Sugerente, también, resulta la idea de F. Rodríguez Adrados, 1996, p. 129, quien observa una estructura en anillo delimitada por la tradición antitiránica expuesta por Tales del comienzo y la intervención final de Anacarsis desplazando a Periandro por haber 
cuales, en nuestra opinión, no resuelve la propuesta de Aune ${ }^{13}$, con frecuencia citada. Así, el diálogo, siguiendo en ello el modelo platónico, comienza súbitamente, en medio de una conversación entre Diocles y $\mathrm{Nicarco}^{14}$. Un diálogo epistolar que nos avisa de un carácter pedagógico-moralizante ${ }^{15}$ imprescindible para la comprensión de la obra, en el que Plutarco, a través de Diocles, adopta, desde el principio, como el viejo y sabio maestro, el papel

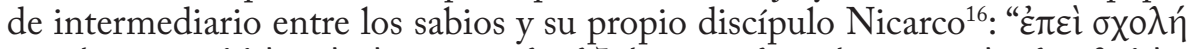

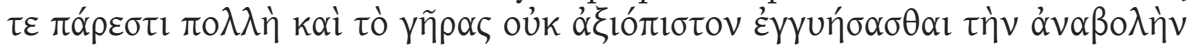

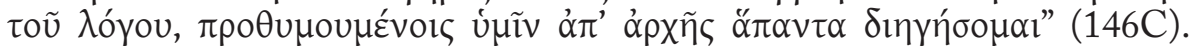
A continuación, el relato del paseo del narrador Diocles con Tales, que nos retrotrae al de los participantes del Banquete de Jenofonte o al de Sócrates y Fedro en el diálogo homónimo de Platón, da comienzo a la acción argumental ya encaminada.

2.1. Los siguientes pasajes, que coinciden con los momentos iniciales del banquete ${ }^{17}$, dan ya la pauta temática de la obra, jalonada por anécdotas que ponen de relieve la competencia de los Sabios en toda suerte de saberes prácticos (p. ej. la medición de la pirámide por Tales, citada en 147A). Dichas habilidades se hacen patentes mediante el relato de anécdotas con un tono de buen humor ${ }^{18}$, propio de todo banquete, como cuando Diocles $(147 \mathrm{C})$

ejercido la tiranía.

${ }^{13}$ D. E. Aune, 1972, pp. 56-8, divide la pieza en: I. "Prooímion” histórico (cap. 1); II. Composición narrativa introductoria (caps. 2-5); III. El "sympósion": conversación principal (caps. 6-21). Tal esquema nos parece insuficiente para una comprensión global en el marco del género al que pertenece.

${ }^{14} \mathrm{Al}$ margen de posibles resonancias (cf. J. Defradas, 1985, p. 179), son nombres ficticios, muy habituales en la época: M. D. Gallardo, 1972, p. 182. Más provechoso nos parece detectar el posible alterego del autor en la figura de Diocles.

${ }^{15}$ En este sentido, A. Busine, 2002, p. 101, habla de una obra "relativement scolaire", si bien, con E. SuÁrez de la Torre, 2005, p. 474, no compartimos el juicio que añade de que el autor "ne s'est pas particulièrement illustré dans la reprise et l'adaptation des éléments traditionnels de la syllogè".

${ }^{16}$ El diálogo-simposio y su función al servicio de la paideia, previsto por el fundador de la Academia, seguían vigentes: cf. E. SuÁrez de la Torre, 2005, pp. 480-1.

${ }^{17}$ A través de Tales (147D-148B), Plutarco ilustra su concepto simposial - cf. Quaest. Conv. 686D -, basado en 3 principios: 1. adecuada preparación - de los nobles a los que se dirige la "carta" de Nicarco - para el banquete, porque "es más difícil encontrar el adorno conveniente al carácter, que el adorno superfluo e inútil para el cuerpo”. Introduce comparaciones alusivas al mal comensal que "es capaz de destruir y estropear" el mejor vino, comida o canto, considerando las consecuencias negativas de "cuando la insolencia o el enfado han surgido por causa del vino". 2. "el aceptar compartir el banquete con unos comensales elegidos al azar es propio de un hombre poco inteligente”, y, por ello, Quilón no aceptó la invitación hasta conocer los nombres de cada uno de los invitados. 3. la costumbre egipcia de colocar una momia junto a los comensales (citada por Hdt. II 78), que "aporta alguna ventaja, si impulsa a los comensales no a la bebida y al placer, sino a la amistad y al afecto mutuo y los exhorta a no hacer una vida, que es muy corta por el tiempo, larga por sus malas acciones", es el cierre paradigmático de su concepto de simposio. De hecho, Plutarco sigue el modelo jenofonteo en el que las etapas del banquete real marcan la pauta de la conversación (cf. J. Martin, 1931, p. 259, n. 2; J. Mossman, 1997, p. 129).

${ }^{18}$ Ciertamente, la combinación de un tono serio con otro cómico es la atmósfera característica desde Jenofonte (cf. J. Martin, 1931, pp. 1-32; J. Mossman, 1997, p. 122). Así, D. L. Gera, 
recuerda la anécdota del muchacho que tiraba piedras a un perro y, habiéndole dado a la suegra, exclamó "Tampoco así está mal" (cf. De tranq. anim. 467C), en el fondo, una alegoría del buen gobernante que sabe cambiar el paso: $\delta$ io

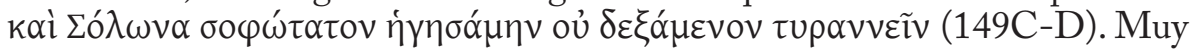
divertida también es la que narra el prodigio de una cría de yegua, mitad humana y mitad équido, presagio de la ruina de la familia de Periandro, y que Tales interpreta menospreciando los ritos purificadores de Diocles: "mi consejo es que no emplees a hombres tan jóvenes para guardar a los caballos, $\mathrm{o}$ proporciónales mujeres" (149E).

En 148D aparece en escena - pues mucho hay de teatro en los banquetes literarios - Eumetis o Cleobulina ${ }^{19}$, por ser hija de Cleóbulo de Lindos, pero también por su proverbial "sagacidad para los enigmas y su sabiduría". Junto a ella ${ }^{20}$, otro invitado especial a tan selecto grupo es Esopo, paradigma de la sabiduría popular ${ }^{21}$, cuyas fábulas serán el contrapunto a las intervenciones de los Sabios.

El banquete ya está en marcha con los personajes precisos, mientras los Sabios $\sigma \circ \varphi \tilde{\omega} v k \alpha \dot{\gamma} \gamma \alpha \theta \tilde{\omega} v \alpha \mathfrak{\alpha} v \delta \rho \tilde{\omega} v(150 \mathrm{C})$ hacen gala de una moderación muy del gusto de nuestro sacerdote de Apolo, y que está en consonancia con el buen gobierno sobre el que se va a conversar tras terminar la comida ( $\underline{1^{a} \text { fase }}$ del banquete).

2.2. Entre los capítulos 6-12 se aborda el tema del gobierno del Estado, recordando al legendario faraón Amasis, no a través de acciones concretas sino de su capacidad para resolver enigmas, como cuando pide ayuda a Bías para resolver la prueba del rey etíope (151B-E), que le prometió que, si se bebía todo el mar, se quedaría con la isla Elefantina, a lo que Bías le aconseja responder que primero "contuviera los ríos que van a parar al océano". La conclusión es que las enseñanzas de los Sabios forman al buen gobernante. Tras la intervención de Solón (cap. 7, 151F-D), conoceremos la prueba a la que, a modo de réplica (152E), somete Amasis al rey etíope, y cuyo "mensaje

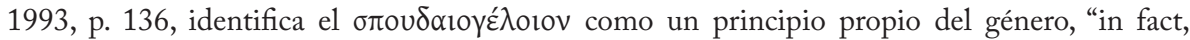
particularly associated with Socratic symposia in ancient times".

${ }^{19}$ Con D. F. LEÃo, 2005, p. 349, podemos entrever también una propuesta didáctica en la inclusión de este personaje femenino, un tanto sorprendente en el ambiente masculino de la tradición simposíaca: "Cleobulina contribui, também, para transformar o espaço do banquete numa cosmópolis dos vários tipos de sapiência: ela representaria, assim, uma sabedoria mais simples, permeada de intuição política e humanidade”. J. Mossman, 1997, p. 134, apunta que la escena "it provides a healthy diet of philosophical and political thought leavened with lively characterization and picturesque setting which the conversation, sometimes with undertones of irony and sadness, brings vividly to life".

${ }^{20}$ La presencia simultánea de Cleobulina y Esopo no es casual. Así, cuando Cleodoro siente ofendida su virilidad por la presencia de ésta (153E-154C), Esopo defiende su asistencia. Vid. la interpretación de D. F. LEÃo, 2005, p. 349: "ao colocar-se ao lado de Cleobulina, está também a defender a mesma sabedoria popular que ele próprio representa”.

${ }^{21}$ J. Martin, 1931, p. 58, compara el papel de Esopo con el de Aristófanes en el Banquete de Platón, en su condición de representantes de una cultura más popular que otros participantes. Por su parte, S. JeDrkiewicz, 1997, pp. 49-52, observa que el autor se sirve del personaje de Esopo para introducir a través de sus fábulas las respuestas que le interesaban de los Sabios. 


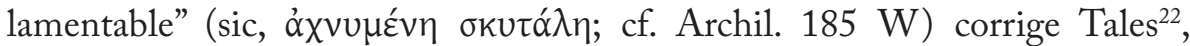

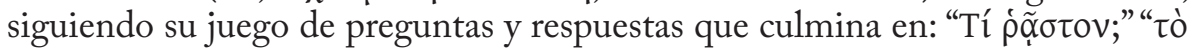

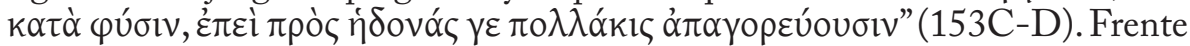
al aparente alejamiento del Banquete del maestro Platón visto por algunos, el eco de su pensamiento comienza a atisbarse en esta declaración de principios plutarqueos.

Sin embargo, esta suerte de recopilación de saberes no estaría completa sin contar con Hesíodo ${ }^{23}$, a quien Plutarco introduce (cap. 10) en certamen con Lesques, autor de la Pequeña Ilíada, y no con Homero, obteniendo el de Ascra el trípode de la victoria en los funerales de Anfidamante. La autoridad de sus poemas se equipara a la de los enigmas que se plantean en la conversación.

2.3. Agotado el tema del gobierno del Estado, Diocles introduce el del

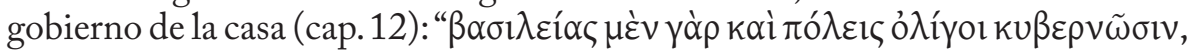

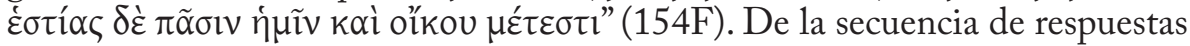
de los presentes ${ }^{24}$, destacamos la de Quilón, a través del cual el autor conecta el gobierno de la casa con el político. Éste ilustra su faceta política con la respuesta que dio Licurgo a alguien que le aconsejaba establecer una democracia en su ciudad y al que contestó "primero establece en tu casa una democracia".

El final del turno de respuestas sirve a Plutarco para retardar la narración e introducir el tema de la bebida ${ }^{25}$ en el banquete (cap. 13), que deja clara su

${ }^{22}$ La coincidencia con la Vida de Tales de D. L. I 35 demuestra, para A. Busine, 2002, p. 96, la gran dependencia de este relato de las fuentes antiguas, especialmente en lo referente a sentencias y apotegmas. Sin embargo, con C. Morales Otal \& J. García López, 1986, p. 241 n. 96, quizás no sean palabras reales de Tales sino un reflejo del pensamiento platónico y neoplatónico.

${ }^{23}$ Ciertamente, como apunta V. J. Gray, 1998, p. 160 - siguiendo a M. L. WEst, 1978 -, Trabajos y días debe ser considerada el primer testimonio de una tradición de "wisdom literature", de honda raigambre oriental, en la que se instalará la tradición sapiencial de los Sabios. Posteriormente, la propia poesía de sus representantes constituye el vehículo de propagación de su ideario (J. Vela TEJADA, 2008, p. 506), hasta llegar al siglo IV en el que la escuela socrática - A. Busine, 2002, p. 99, habla de "reprise du genre littéraire du logos oikonomikos"- habría jugado un papel destacado en el paso al ámbito de la prosa del pensamiento práctico (como las $\chi \rho \varepsilon \tilde{\alpha} \alpha 1$ de Aristipo, contemporáneo de Sócrates, citado por D. L. 2.48 y 86). Esta larga tradición gnomológica queda configurada definitivamente en época helenística, a partir de sentencias y apotegmas atribuidos a los Sabios, de los que es deudor el polígrafo de Queronea (cf. A. Busine, 2002, p. 102: "le matériel gnomologique et apophtegmatique utilisé par Plutarque constituerait même, pour ainsi dire, l'armature du dialogue"). En definitiva, como propone R. P. Martin, 1993, p. 123, "The "sympotic" strain in the stories of the Seven Sages (as in the tale of their banqueting together) would not, then, be a recent invention, but a relic of a much older context", por lo que el Banquete plutarqueo sería "an expression of a continuing tradition, not just Plutarch's innovation", sin menoscabo de su aportación personal.

${ }^{24}$ Cada uno de los contertulios responde de acuerdo con su perfil: Esopo con la fábula de la zorra y la pantera que ilustra la belleza interior "de los que habitan una casa honrada y feliz"; Solón propugna que la adquisición de riquezas sea sin mediar injusticia y que sean gastadas con mesura; Bías habla del respeto a las leyes dentro y fuera de casa; Tales prefiere la casa que permite disfrutar del mayor descanso; Cleóbulo alaba al dueño que tiene más gente que lo quiera que lo tema; y para Pítaco la ideal es la que no necesita nada superfluo ni carece de lo necesario.

${ }^{25}$ Las consecuencias de la ingesta excesiva de vino es un tema recurrente en la tradición: en el Banquete de Jenofonte, con el personaje del bufón Filipo (1.11-16), y en el de Platón, al que 
voluntad de adscripción al género al marcar el tiempo interno del banquete (cf. cap. 5). Los consejos al respecto de Hesíodo y Homero vuelven a convertir a la épica en fuente de sabiduría.

Tras este paréntesis, entre los caps. 14 y 16, se retoma en detalle la discusión sobre el gobierno de la casa ${ }^{26}$. Los temas se suceden perfectamente engarzados: abre Quersias (157A) planteando la cuestión de la medida de la propiedad adecuada para cada individuo, ideal imposible para Cleóbulo, quien, en conversación con el médico Cleodoro, lo compara con la dosis de los medicamentos: "También tú [...] a tus enfermos no les recetas lo mismo a todos, sino a cada uno lo que le conviene". Ello sirve para introducir el tema de la dieta, para el cual Solón alude como autoridad a la "dieta de Epiménides", si bien finalmente prefiere a Hesíodo, presente a lo largo de todo el tratado, pero con un protagonismo especial en estos párrafos en los que es reconocida

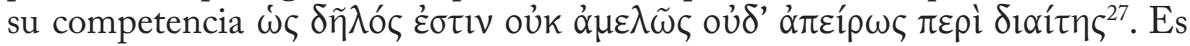
éste un pasaje decisivo para entender este tratado, tan extraño para algunos críticos, porque nos está ofreciendo las claves del pensamiento de Plutarco, aquí más délfico que nunca. Establecida la primacía de Hesíodo, Cleodoro inviste a Esopo, el octavo Sabio, como discípulo de aquél "con más derecho que Epiménides" 28 , y se atribuye al fabulista "el origen de esa hermosa y variada sabiduría” (158B), lo que demuestra la conciencia de una tradición sapiencial por parte del autor.

No obstante, a lo largo de los capítulos 15 y 16, el tema del régimen de vida va a adquirir una nueva dimensión que pone de relieve la clara conexión concurre Alcibíades en lamentable estado (212b sqq.). Cf. J. Vela TEjadA, 2007, p. 33.

${ }^{26}$ Como indica A. Busine, 2002, p. 99, "Le thème de l'oỉkovouía permet ainsi à Plutarque d'évoquer le rapport entre gouvernement de la cité et gestion domestique". No obstante, la presencia de estos contenidos adquiere una especial relevancia desde el punto de vista literario, pues se atribuye a la tradición socrática la atención a estos temas: cf. F. Roscalla, 1990. Ello reforzaría la idea de quienes, como D. Musti, 2001, p. 89, intuyen el influjo socrático sobre el simposio: "Il ruolo del socratismo nel ripensamento globale della vita è decisivo. E poiché il socratismo segna la nascita della filosofia in senso stretto, in quanto riflessione sistematica sui principi dell'essere, del conoscere e del dover essere (perciò, della realtà, della conoscenza e della morale), è chiaro che proprio la riflessione dell'ambiente socratico decide il destino di una pratica sociale che al socratismo certo preesisteva, ma che quella cultura filosofica ha scelto come luogo privilegiato di comunicazione". Los últimos años del siglo $\mathrm{V}$ y primeras décadas del IV serían los de la maduración de la consideración filosófica de esta práctica social. A este respecto J. Martin, 1931, p. 124, relativiza la influencia de Sócrates, quien "provides a sort of endpoint". Pese a admitir el modelo socrático en la vinculación del diálogo a Delfos, en su temática política y en la presencia de fábulas esópicas, concluye que éstas fueron marginales dentro de su actividad.

${ }^{27} \mathrm{Y}$ es que, en efecto, en Hesíodo, se encuentra ya una detallada guía, aquí reproducida (158A-B), sobre el régimen de comidas (Trabajos 559 sqq.), la mezcla del vino (Trabajos 592-5), el valor del agua (Trabajos 735-741), del baño (Trabajos 753), sobre las mujeres (Trabajos 373-5 y 699-705), el tiempo propicio para la relación sexual (Trabajos 735-6 y 812) y el modo como se han de sentar los recién nacidos (Trabajos 750-2). Cf. C. Morales Otal \& J. García López, 1986, p. 257.

${ }^{28}$ La común utilización por parte de Esopo (4 y 4a Perry) de la fábula del halcón y el ruiseñor, que relatara Hesíodo (Trabajos 203 sqq.), es para Cleodoro el argumento de peso a favor del fabulista. 
para Plutarco entre sociedad e individuo, destinatario de su $\pi \alpha 1 \delta \varepsilon i ́ \alpha$. Inquirido Solón por Cleodoro sobre su modelo, y respondiendo aquél que "de los bienes mayores y más importantes, el segundo es necesitar muy poco alimento" y,

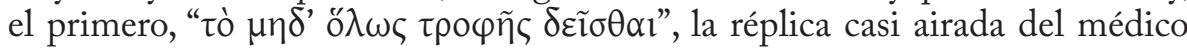
introduce principios propios del estoicismo ${ }^{29}$ sobre la condición humana, cuya vida "se consume en una serie de trabajos", la mayoría de los cuales los provoca

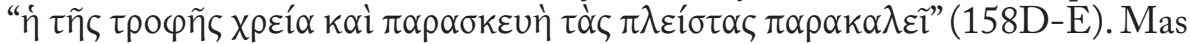
la necesidad constituye el principio de nuestra civilización: el hambre nos llevó a la invención de la agricultura, ésta a las artes y oficios, de éstos se pasó a las honras a los dioses y el respeto a los dioses nos llevó a practicar los placeres de Afrodita en la intimidad de la noche y no al aire libre como bestias. En suma, "el que no necesita alimento tampoco necesita el cuerpo y eso sería no tener necesidad de sí mismo" (159A). La respuesta de Solón ${ }^{30}$, que ocupa todo el cap.

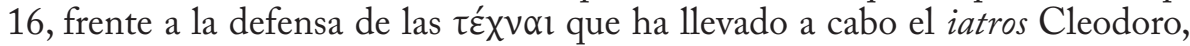
sirve a Plutarco para realizar una declaración de principios religioso-filosófica, que se apoya en el prestigio de Solón ${ }^{31}$, quien ocupa el primer asiento por saber y edad ${ }^{32}$. En efecto, comenzando con planteamientos órficos, que postulan la impureza de la carne y, por ende, la prohibición de su ingesta, Solón considera la alimentación como un signo de esclavitud del ser humano: la única salida es

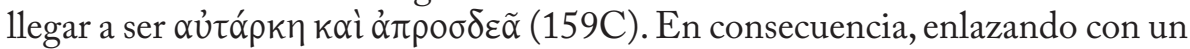

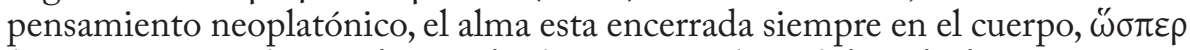

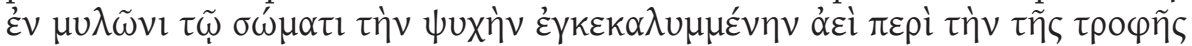

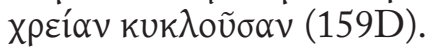

A partir de aquí, Plutarco hace patente su casi devota fidelidad al pensamiento de Platón, como cuando Solón prosigue diciendo "por falta de conocimiento de las cosas bellas, nos contentamos con una vida basada en las obligaciones" (160C), lo cual, sin duda, desdice a quienes quisieron ver un alejamiento del Banquete de Platón ${ }^{33}$. En definitiva, concluye el primero de

${ }^{29}$ Cf. C. Morales Otal \& J. García López, 1986, p. 259 n. 164.

${ }^{30}$ M. D. Gallardo, 1972, p. 186, considera que el discurso de Solón está inspirado en el de Sócrates en el Fedón 64a-67b de Platón.

${ }^{31}$ En dicha consideración sigue la opinión de su venerado maestro Platón, quien a través de Critias (Ti. 20d), había calificado a Solón como "el más sabio de los Siete": cf. J. Vela Tejada, 2008, p. 505. G. J. D. Aalders, 1977, p. 29, empero, se sorprende de que Plutarco "father his platonizing ideas on the Seven Sages, especially on Solon, who as a rule were considered to be the prominent representatives of a more practical and pedestrian wisdom".

${ }^{32}$ Así lo relata en $151 \mathrm{E}$, cuando Quilón dice "que era justo que Solón comenzara la disertación, no sólo porque aventajaba a todos por la edad y estaba casualmente sentado el primero, sino porque ejercía el poder más elevado y perfecto por haberles dado a los atenienses sus leyes": vid. J. Vela Tejada, 2008, p. 512.

${ }_{33}$ No cabe duda de que las palabras de Solón nos traen resonancias de la intervención de la enigmática Diótima (209e-212a) en el Banquete platónico, en uno de los episodios más renombrados en el que se describen los pasos necesarios para alcanzar el ideal de perfección

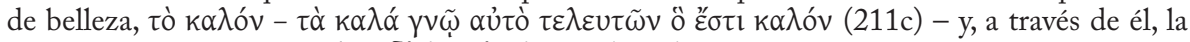

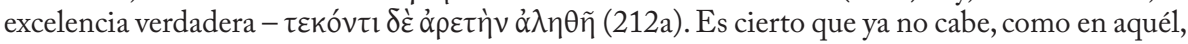
el elogio del amor homosexual como modelo de perfección, pero es que el de Queronea no hace sino seguir algo que ya se había anticipado en la obra homónima de Jenofonte (una comparación entre ambos testimonios puede encontrarse en J. VELA TEJADA, 2007, pp. 35 sqq.), en la que los 
los Sabios, el alma alimenta el cuerpo con esfuerzo y dedicación pero, si fuera

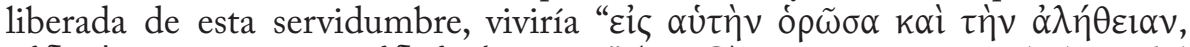

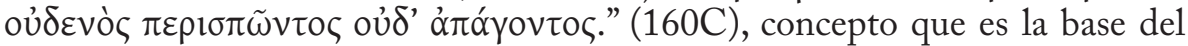
pensamiento de Platón ${ }^{34}$. No obstante, por si nos cabe alguna duda de su sentido

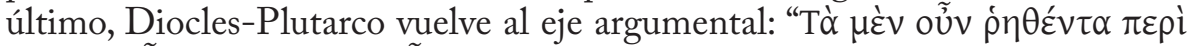
$\tau \rho \circ \varphi \tilde{\eta} \varsigma, \tilde{\omega} N^{\prime} \kappa \alpha \rho \chi \varepsilon, \tau \alpha \tilde{v} \tau$ ' $\tilde{\eta} v^{\prime \prime}$.

2.4. Como el Alcibíades del Banquete de Platón o el empresario siracusano que llega con su compañía de actores en el de Jenofonte, la irrupción súbita de Gorgo ${ }^{35}$, el hermano de Periandro que entra "cuando todavía estaba hablando Solón”, rompe el hilo argumental y, a través de una larga intervención (caps. 17-20), a caballo entre el relato verídico y el mito ${ }^{36}$ (como el del antropoide en Platón o el mimo sobre los amores de Dioniso y Ariadna representado en el de Jenofonte), introduce la leyenda etiológica del músico Arión ${ }^{37}$, que ilustra los principios de la Providencia divina que rigen el gobierno del Universo ${ }^{38}$, principios que nuestro autor resume en la máxima délfica por excelencia ${ }^{39}$, "nada en demasía", puesta en boca de Quilón. Esta máxima da pie, en el capítulo final, a una animada discusión en la que se entremezcla la devoción a Delfos ${ }^{40}$,

misterios del amor que conducen a la perfección, se realizan a través del amor heterosexual y conyugal (1.10). Esta es, de hecho, la tesis principal del trabajo de J. Mossman, 1997, pp. 12634: "its deliberate omission of homosexual themes and its substitution of heterosexuality into the traditional symposion context" (p. 134).

${ }^{34}$ Cf. A. Busine, 2002, pp. 98-9.

${ }^{35}$ J. Mossman, 1997, p. 131, subraya que "the arrival of Gorgos structurally resembles de arrival of Alcibiades in Plato in that it changes the direction of discussion". La del empresario siracusano que va a representar el mimo de Dioniso y Ariadna en el de Jenofonte tiene la misma función estructural, lo cual implica un rasgo de género y no una mera imitación: cf. J. VELA TEJADA, 2007, p. 35 .

${ }^{36}$ M. D. Gallardo, 1972, p. 186, habla de "las páginas más elevadas de toda la obra” y subraya que Plutarco sigue "la técnica platónica del diálogo, según la cual se introduce un mito lleno de belleza y poesía y de él se sacan conclusiones fundamentales”. Y no sólo en el de Platón. Debe destacarse que hay una adecuación argumental al contexto simposiaco: a Arión se atribuye la invención del ditirambo, asociado al culto dionisíaco, y el mimo representado en el jenofonteo versa sobre los amores de Dioniso y Ariadna.

${ }^{37}$ Sobre el mito de Arión, J. Mossman, 1997, p. 131, opina que "not arbitrary chosen, but sum up some of the most important themes of the dialogue, including the theme of love". En nuestra opinión, la tendencia de su estudio a reducir al tema amoroso el significado de la obra, con ser importante, hace que se le escape el profundo sentido délfico de un mito que, con A. Busine, 2002, p. 101, "devait faire parties du patrimoine delphique à la disposition de Plutarque".

${ }^{38}$ Como apunta M. D. Gallardo, 1972, p. 187, la afirmación de Anacarsis, $\psi u x \tilde{\eta} \varsigma$ yò

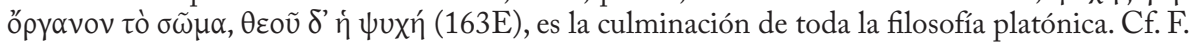
Rodríguez Adrados, 1996, p. 129: "en definitiva, lo que se hace es pasar del gobierno de los hombres al gobierno de Dios: todo está calculado”.

${ }^{39}$ En este sentido, seguimos a A. Busine, 2002, p. 97, cuando afirma que "Il n'y a pas de grande surprise à ce que la prête d'Apollon eut recours aux maximes delphiques", que una larga tradición había asociado a los Siete Sabios (cf. Demetrio, FGrHist 228 F 114; Diodoro IX 10.1-4).

${ }^{40}$ Suscribimos las palabras de E. SuÁrez de LA Torre, 2005, p. 474, para quien la tradición de los Siete Sabios tiene una indiscutible impronta délfica - que también explicaría la presencia de Esopo -, "aunque luego se ha convertido en un bien "mostrenco" de las sucesivas etapas de 
el significado de sus máximas, la autoridad sapiencial de los Sabios ligados a ellas y el vínculo de las fábulas de Esopo con esta tradición(164B), culminando la narración en el destino al que el autor nos quería llevar: la renacida autoridad del santuario de Apolo. En este contexto, los juegos literarios sobre otras máximas y anécdotas délficas llevan a los comensales a la noche, referencia temporal que confirma la atención al canon simposiaco, aquí (164D) a través de la cita erudita del verso homérico ${ }^{41}$ :

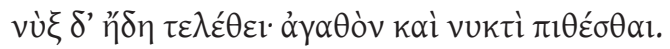

(Il.7.282 y 293)

3. Llegados al final de la obra, es, pues, el momento de establecer las conclusiones a las que el propio autor nos ha llevado:

- La obra no es una recopilación inconexa de anécdotas sino que muestra un esquema claro en el que los temas de sabiduría práctica, propios de los protagonistas, actúan como elemento aglutinador. Así, se pasa del buen gobierno $^{42}$ del Estado al buen gobierno de la casa, de éste al buen gobierno/ cuidado del cuerpo, del cuerpo al alma y de esta a Dios, con su sede en Delfos y sus principios apolíneos resumidos en la máxima: nada en demasía ${ }^{43}$. En consecuencia, dado el carácter práctico de las máximas délficas, el Banquete de los Siete Sabios no podía seguir al pie de la letra el modelo de Platón y sí otros referentes más cercanos a la tradición sapiencial.

- Del mismo modo, con mayor claridad que en cualquier otra de sus obras dialógicas o de temática socrático-platónica, el Banquete plutarqueo se enmarca claramente en el esquema de dicho género literario ${ }^{44}$. El diálogo simposiaco,

la cultura griega". Por ello, no comparte la idea de A. Busine, 2002, p. 102), de que la leyenda esté desprovista de su sentido inicial, "sino que más bien lo veo recuperado, en cuanto a la reivindicación apolínea y religiosa que preside esta obra, sobre todo a partir de la entrada en escena de Gorgo, el hijo de Periandro, y el relato del rescate de Arión”.

${ }^{41}$ La idea de prevenir una deriva "indeseada" une los Banquetes jenofonteo y plutarqueo: vid. J. Vela Tejada, 2007, p. 35. Así, J. Mossman, 1997, p. 134, señala que "Solon's bringing the dialogue to an abrupt end, we feel, prevents the conversation straying further on to dangerous ground, as the irony of Periander's disastrous marriage break-up threatens to re-emerge".

${ }^{42}$ Vid. A. Busine, 2002, p. 94: "l'objectif caché de Plutarque fut de décrire un banquet exemplaire pour ses contemporains dont le thème central, récurrent dans la littérature de cette époque, était l'oikovouía des États, des maisons et du Cosmos".

${ }^{43}$ Un simposio délfico de principio - cuando Plutarco se nos disfraza de Diocles, sacerdote purificador - a fin, por ser Delfos sede de la sabiduría máxima que todo joven bien instruido debe seguir para alcanzar las máximas metas. Así, J. Sirinelli, 2000, p. 205, pone de relieve que el Banquete fue escrito poco después de que Plutarco fuera nombrado sacerdote en Delfos. En una línea similar, A. Busine, 2002, p. 94 subraya "la volonté de Plutarque de sauver de l'oubli et de réactualiser le capital culturel de Delphes".

${ }^{44}$ No compartimos la afirmación de J. Sirinelli, 2000, p. 160, de que "est une imitation directe de Platon", aunque sí coincidimos en que Plutarco percibiera "les possibilités que lui offrait le dialogue pour exposer les idées qui par ailleurs faisaient l'objet de son enseignement". Tampoco nos parece, como añade, que se viera obligado a abandonar una tradición para la que no estaba dotado como Luciano: "semble avoir quelque peu hésité dans la conception même du banquet et avoir cédé à des sollicitations divergentes; l'une plutôt pédagogique, visant à donner 
desde la tradición socrática, reemplaza a la poesía como marco sapiencial y cada autor adopta libremente los temas de discusión, lo que explica las lógicas "desviaciones" del referente de Platón. Por otra parte, la introducción de temas de carácter práctico y la preeminencia del eros heterosexual y conyugal frente al homoerotismo platónico - está perfectamente atestiguado desde los comienzos del género en prosa en la obra de Jenofonte.

- En definitiva, nos hallamos ante un ejemplar de carácter didáctico, con pinceladas del género epistolar en su forma, dirigido a los jóvenes aristócratas, futuros gobernantes del Imperio romano, cuyo paradigma de conducta se encuentra en las máximas de los Sabios - la mayoría de los cuales habían ejercido el poder -, como cuando Tales afirma que "Un tirano que prefiera gobernar a esclavos más que a hombres libres en nada se diferencia de un agricultor que prefiera recolectar cizaña y malas hierbas en lugar de trigo y cebada." (147C). Los ideales que emanan de este banquete délfico son el buen gobierno y la filantropía, como en las ya citadas cualidades encarnadas por

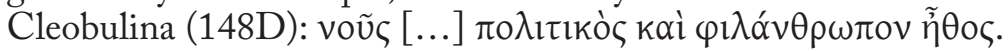

\section{Bibliografía CITADA}

Aalders, G. J. D., "Political thought in Plutarch's Convivium Septem Sapientium”, Mnemosyne, 30.1 (1977) 28-39.

Plutarch's Political Thought, Amsterdam/Oxford/Nueva York, 1982.

Aune, D. E., "Septem sapientium convivium”, en H. D. Betz (ed.), Plutarch's Theological Writings and Early Christian Literature, Leiden, 1972, pp. 51105.

\section{Busine, A., Les Sept Sages de la Grèce Antique. Transmission et utilisation d'un patrimoine légendaire d'Hérodote à Plutarque, París, 2002.}

dans un panorama de la philosophie quelques lumières sur les diverses origines de la sagesse hellénique, l'autre, plutôt esthétique, visant à composer un nouveau type de banquet; les deux objectifs ne se marient pas avec bonheur, l'un embarrassant l'autre" (p. 162). No parece que esta obra entusiasme a la escuela francesa, porque también dice A. Busine, 2002, p. 93: "Malgré le déploiement de grands efforts pour esquisser une scène pittoresque, le prête de Delphes ne s'est malheureusement pas illustré pour son habilité dans l'écriture du dialogue légendaire". En una línea más productiva, F. Rodríguez Adrados, 1996, p. 136, admite la cercanía al género del banquete socrático-platónico, pero partiendo de una tradición helenística escrita. No compartimos, empero, la influencia de los modelos cínicos más allá de la inclusión, como sabio, del cínico Anacarsis, que reemplaza a Periandro en el grupo por su condición de tirano: "Estos Banquetes cínicos de los Siete Sabios han sido la base, sin duda, del Banquete de Plutarco, que los ha reelaborado, sin renunciar, sin duda, a introducir más material de los mismos orígenes"(p. 139). Estos hipotéticos Banquetes estaban relacionados con el de Menipo, del que poco sabemos (cf. J. Martin, 1931, p. 211 sqq.), que influyó en el de Plutarco y en los de Meleagro, Lucilio, Varrón, Horacio, Petronio, Luciano y los julianos. No lo tiene tan claro D. F. LEÃo, 2005, p. 345: "Menos evidente se afigura, no entanto, a hipótese de existir uma ou várias obras de premeio". En suma, aunque, en su forma, derivaba lógicamente de "viejas tradiciones", es plenamente original en su contenido. 
Gallardo, M. D., "Estado actual de los estudios sobre los simposios de Platón, Jenofonte y Plutarco", CFC, 3 (1972) 127-91.

Gera, D. L., Xenophon's Cyropaedia. Style, Genre, and Literary Technique, Oxford, 1993.

Gray, V. J., "Xenophon's Hiero and the Meeting of the Wise Man and Tyrant in Greek Literature", CQ, 36 (1986) 115-23.

"Xenophon's Symposion: The Display of Wisdom”, Hermes, 120 (1992) $58-75$.

The Framing of Socrates: The Literary Interpretation of Xenophon's Memorabilia, Stuttgart, 1998.

Hauck, G., Plutarch von Chaeronea, der Verfasser des Gastmabl der 7 Weissen, Diss. Würzburgo-Burghausen, 1893.

Jedrkiewicz, S., Il convitato sullo sgabello: Plutarco, Esopo ed i Sette Savi, Roma, 1997.

LeÃo, D. F., "Plutarco e a tradição dos Sete Sábios", en M. Jufresa et al. (eds.), Plutarc a la seva època: Paideia $i$ societat. Actas del VIII Simposio Internacional de la Sociedad Española de Plutarquistas (Barcelona, 6-8 Noviembre, 2003), Barcelona, 2005, pp. 343-51.

Martin, J., Symposion, Paderborn, 1931.

Martin, R.P., “The Seven Sages as Performers of Wisdom”, en C.Dougherty \& L. Kurke (eds.), Cultural Poetics in Ancient Greece: Cult, Performance, Politics, Cambridge, 1993, pp. 108-28.

Mossman, J., "Plutarch's Dinner of the Seven Wise Men and its place in symposion literature", in J. Mossman (ed.), Plutarch and his Intellectual World, Londres, 1997, pp. 119-40.

Musti, D., Il simposio, Roma-Bari, 2001.

NoËL, M.-P., “Symposion, philanthrôpia et empire dans la Cyropédie de

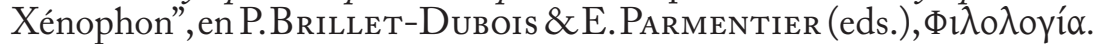
Mélanges offerts a M. Casevitz, Lyon, 2006, pp. 133-46.

Paladini, M.-L., "Influenza della tradizione dei Sette Savi nella Vita di Solone di Plutarco", REG, 69 (1956) 377-411.

Rodríguez Adrados, F., "Géneros helenísticos en el Banquete de los Siete Sabios”, en J. A. Fernández Delgado \& F. Pordomingo Pardo (eds.), Estudios sobre Plutarco: aspectos formales. Actas del IV Simposio Español sobre Plutarco (Salamanca, 26-28 de Mayo, 1994), Madrid, 1996, pp. 125-42.

Roscalla, F., "Influssi Antistenici nell'Economico di Senofonte", Prometheus, 16 (1990) 207-16. 
Sirinelli, J., Plutarque de Chéronée: un philosophe dans le siècle, París, 2000.

Snell, B., "Zur Geschichte von Gastmahl der Sieben Weissen", en B. Snell, Gesammelte Schriften, Göttingen, 1966.

SuÁrez de la Torre, E., “Diálogo, filosofía y simposio”, en M. Jufresa et al. (eds.), Plutarc a la seva època: Paideia i societat. Actas del VIII Simposio Internacional de la Sociedad Española de Plutarquistas (Barcelona, 6-8 Noviembre, 2003), Barcelona, 2005, pp. 463-83.

Teodorsson, S.-T., "Principles of Composition in the Quaestiones Convivales", en J. A. Fernández Delgado \& F. Pordomingo Pardo (eds.), Estudios sobre Plutarco: aspectos formales. Actas del IV Simposio Español sobre Plutarco (Salamanca, 26 a 28 de Mayo, 1994), Madrid, 1996, pp. 3948.

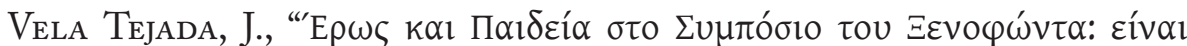

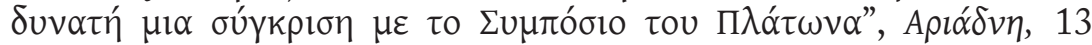
(2007) 29-47.

"El Banquete de los Siete Sabios y la Vida de Solón de Plutarco: mito político y contexto literario", en A. G. Nikolaidis (ed.), The Unity of Plutarch's Work: Moralia Themes in the Lives, Features of the Lives in the Moralia, Berlín/Nueva York, 2008, pp. 501-14.

West, M. L., Hesiod. Works and Days, Oxford, 1978.

Wilamowitz, U.von, “Zum Gastmahl der Sieben Weisen”, Hermes, 25 (1890) 196-227.

Ediciones y traducción en español del Septem sapientium convivium

Bаввітт, F. C. (ed.), Plutarch's moralia, vol. II, Cambridge, Mass.: Harvard University Press, 1928, (repr. 1962).

Defradas, J. et al., Plutarque. Euvres morales, tome II, París, 1985.

Morales Otal, C. \& García López, J., Obras morales y de costumbres, vol. II, Madrid, 1986. 